\title{
Genetic Algorithm Based PID Controller Tuning Approach for Continuous Stirred Tank Reactor
}

\author{
A. Jayachitra ${ }^{1}$ and R. Vinodha ${ }^{2}$ \\ ${ }^{1}$ Department of Electronics and Communication Engineering, V.R.S College of Engineering \& Technology, Villupuram 607 107, India \\ ${ }^{2}$ Department of Electronics and Instrumentation Engineering, Annamalai University, Annamalai Nagar 608 002, India
}

Correspondence should be addressed to A. Jayachitra; jayachitra98@gmail.com

Received 30 July 2014; Revised 26 October 2014; Accepted 5 December 2014; Published 23 December 2014

Academic Editor: Jun $\mathrm{He}$

Copyright (C) 2014 A. Jayachitra and R. Vinodha. This is an open access article distributed under the Creative Commons Attribution License, which permits unrestricted use, distribution, and reproduction in any medium, provided the original work is properly cited.

Genetic algorithm (GA) based PID (proportional integral derivative) controller has been proposed for tuning optimized PID parameters in a continuous stirred tank reactor (CSTR) process using a weighted combination of objective functions, namely, integral square error (ISE), integral absolute error (IAE), and integrated time absolute error (ITAE). Optimization of PID controller parameters is the key goal in chemical and biochemical industries. PID controllers have narrowed down the operating range of processes with dynamic nonlinearity. In our proposed work, globally optimized PID parameters tend to operate the CSTR process in its entire operating range to overcome the limitations of the linear PID controller. The simulation study reveals that the GA based PID controller tuned with fixed PID parameters provides satisfactory performance in terms of set point tracking and disturbance rejection.

\section{Introduction}

PID controllers are still widely used in $90 \%$ of industries, since no other advanced control schemes such as model predictive control, internal model control (IMC), and sliding mode control (SMC) match the simplicity, clear functionality, applicability, and ease of use provided by this controller [1]. PID controller tuned at a particular operating point will not provide a satisfying response when there exists deviation in the process operating range [2]. Hence, soft computing based PID controller tuning is widely proposed by the researchers during the last few decades [3-7].

CSTR process exhibits typical nonlinear and time varying behaviour where control of the parameter reactor concentration with few computation steps is a challenge to the researchers. Therefore, it becomes essential to use powerful heuristic algorithms like GA to tune the PID parameters, thereby achieving good set point tracking and disturbance rejection control in the chemical system CSTR. Vinodha et al. have designed three control schemes for nonlinear CSTR process such as extraction of PID controller parameters based on artificial intelligence, model predictive controllers using the weighted sum of the output from local predictive controllers, and multiple model PID controllers [8]. The presence of parameter uncertainty in nonlinear systems like CSTR has been controlled by designing the nonlinear predictive adaptive controller (NPAC) and a nonlinear disturbance observer (NDO) in literature [9] and the proposed compensation method improves system tracking accuracy and robustness. Prakash and Senthil formulated a nonlinear observer based model predictive controller (NMPC) based on fuzzy Kalman filter (FKF) and augmented state fuzzy Kalman filter (ASFKF) for CSTR process [10]. A model based control scheme (FNMPC) reduces the number of computations needed and is considered as an alternative to analytical model based control scheme as discussed in $[11,12]$.

A partial state feedback controller has been proposed to achieve the global set point tracking control of CSTR [13]. Indirect adaptive control based pole placement and adaptive general predictive control (GPC) methodologies are used to estimate and control parameters of CSTR which has been reported by Delbari et al. [14]. Shopova and VaklievaBancheva have introduced in detail a genetic algorithm called 
BASIC, designed to deal with various engineering optimization problems [15]. The self-organizing GA optimization method has been used for evolving PID controller parameters to avoid premature convergence and to achieve good optimization performance [16]. Krohling and Rey have discussed a method to design an optimal disturbance rejection PID controller based on genetic algorithms for solving the constrained optimization problem in a servo motor system [17]. Kumar et al. have described the design of GA based controller for a bioreactor model that outperformed Ziegler Nichols and Skogestad's tuned controller in terms of overshoot and undershoot as well as disturbance rejection and set point tracking [18]. A modified genetic algorithm has been reported [19] to obtain the optimal PID controller parameters for different process types. Fuzzy gain scheduling has been used to determine the controller parameter transition policy for the dynamic plant [20].

Nagaraj and Murugananth have discussed PID tuning using soft computing based controller, improving the performance of process in terms of time domain specifications, set point tracking, and regulatory changes [21]. In the work of Chang, PID controller has been designed using an artificial bee colony algorithm for an unstable and nonlinear CSTR chemical system [22]. Wang and Jin have determined state feedback linearization control method for nonminimum phase characteristics of CSTR system [23]. Singh and Sharma have proposed a fractional order PID controller with a PSO approach, providing better servo and regulatory response [24]. The combined PID control tuning by coupling the gain-phase margin method with genetic algorithm has been applied for position control in a servo system [25]. A virtual feedback control has been implemented to control the state variables using extended Kalman filter (EKF) in the feedback path using particle swarm optimization technique for CSTR process [7]. In our proposed work to depict the nonlinearity of CSTR process, the differential equation model is used. The methodology proposed is the design of global GA tuned PID values constrained at individual optimum values ISE, IAE, and ITAE and weighted combination of objective functions considered to operate the plant in the entire operating range.

Organization of the paper is presented as follows. Section 2 presents the proposed control approach and Section 3 describes the CSTR plant. Introduction to genetic algorithm is provided in Section 4 and Section 5 includes the simulation results of CSTR process for both servo and regulatory cases. Finally, Section 6 concludes how GA based PID controller gives better performance with minimum computation steps to achieve optimized PID control of the CSTR plant in a wide range.

\section{Proposed Control Approach}

A PID controller is a combination of a proportional, an integral, and a derivative controller, integrating the main features of all three. A simplified block diagram of control approach followed in the work is shown in Figure 1.

From Figure 1, it is inferred that the objective of the work is to tune the PID gains with minimum error between the set value and actual concentration value, where $e$ is

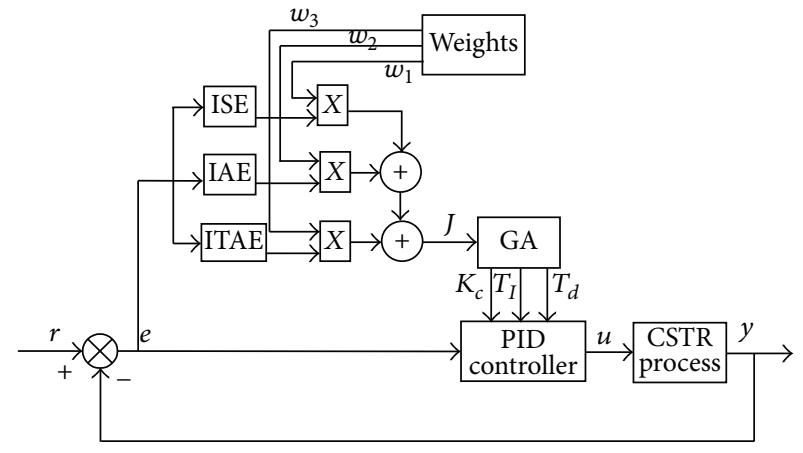

FIgURE 1: Structure of PID controller.

a difference between the desired output $r$ and actual output $y, u$ is the PID control law, and parameters $K_{c}, T_{I}$, and $T_{d}$ are the proportional gain and integral and derivative times, respectively. Commonly employed error criteria to achieve optimized PID tuning values are integral square error (ISE), integral absolute error (IAE), and integrated time absolute error (ITAE), respectively, and are formulated as given in (1), (2), and (3), respectively. From the block diagram, it is clear that a weighted combination of ISE, IAE, and ITAE [4] is used as an objective function to obtain PID parameters through genetic algorithm. Consider

$$
\begin{aligned}
\text { ISE } & =\int_{0}^{\infty}[e(t)]^{2} d t, \\
\text { IAE } & =\int_{0}^{\infty}|e(t)| d t \\
\operatorname{ITAE} & =\int_{0}^{\infty} t|e(t)| d t .
\end{aligned}
$$

The objective function $J$ used in genetic algorithm is defined as

$$
J\left(K_{c}, T_{I}, T_{d}\right)=w_{1}(\mathrm{ISE})+w_{2}(\mathrm{IAE})+w_{3}(\mathrm{ITAE}) .
$$

The PID control law utilized in velocity form is given in

$u(k)$

$$
\begin{aligned}
& =K_{c}\left[(e(k)-e(k-1))+\frac{T}{T_{I}} e(k)\right. \\
& \left.\quad+\frac{T_{d}}{T}(e(k)-2 e(k-1)+e(k-2))\right]+u(k-1) .
\end{aligned}
$$

One or a weighted combination of these criteria is employed to achieve optimized parameter tuning of PID controller. It is generally accepted that weighted indices are more appropriate than individual performance indices as reported in [3-6].

\section{Description of CSTR Process}

The first principles model of the continuous stirred tank reactor and the operating point data as specified by Pottman and Seborg [26] and design procedure described [27] has been used in the simulation studies. In the process considered for simulation study (shown in Figure 2), an irreversible, 


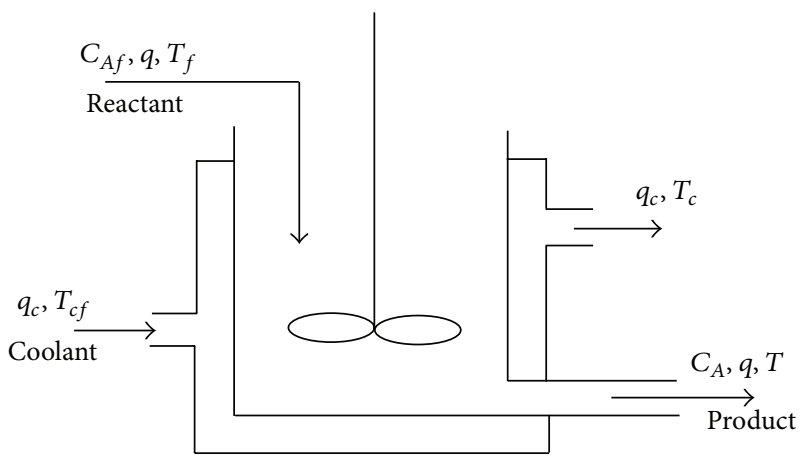

FIGURE 2: Schematic of CSTR process.

TABLE 1: Steady state operating data of CSTR process.

\begin{tabular}{lc}
\hline Process variable & $\begin{array}{c}\text { Normal operating } \\
\text { conditions }\end{array}$ \\
\hline Measured product concentration $\left(C_{A}\right)$ & $0.0989 \mathrm{~mol} / \mathrm{lit}$ \\
Reactor temperature $(T)$ & $438.7763 \mathrm{~K}$ \\
Coolant flow rate $\left(q_{c}\right)$ & $103 \mathrm{lit} / \mathrm{min}$ \\
Process flow rate $(q)$ & $100.0 \mathrm{lit} / \mathrm{min}$ \\
Feed concentration $\left(C_{A f}\right)$ & $1 \mathrm{~mol} / \mathrm{lit}$ \\
Feed temperature $\left(T_{f}\right)$ & $350.0 \mathrm{~K}$ \\
Inlet coolant temperature $\left(T_{c f}\right)$ & $350.0 \mathrm{~K}$ \\
CSTR volume $(V)$ & $100 \mathrm{lit}$ \\
Heat transfer term $(h A)$ & $7 * 10^{5} \mathrm{cal} /(\mathrm{min} \cdot \mathrm{k})$ \\
Reaction rate constant $\left(k_{0}\right)$ & $7.2 * 10^{10} \mathrm{~min}{ }^{-1}$ \\
Activation energy term $(E / R)$ & $1 * 10^{4} \mathrm{~K}$ \\
Heat of reaction $(-\Delta H)$ & $2 * 10^{5} \mathrm{cal} / \mathrm{mol}$ \\
Liquid density $\left(\rho, \rho_{c}\right)$ & $1 * 10^{3} \mathrm{~g} / \mathrm{lit}$ \\
Specific heats $\left(C_{p}, C_{p c}\right)$ & $1 \mathrm{cal} /(\mathrm{g} \cdot \mathrm{k})$ \\
Fouling coefficient $\varphi_{h}(t)$ & 1 \\
Deactivation coefficient $\varphi_{c}(t)$ & 1 \\
\hline
\end{tabular}

exothermic reaction $A \rightarrow B$ (Reactant $A$ of Concentration $C_{A f}$ is converted to Product $B$ of Concentration $C_{A}$ ) occurs in a constant volume reactor that is cooled by a single coolant stream $q_{c}$. The steady state operating specifications are given in Table 1.

The fundamental dependent quantities for the reactor are the total mass of the reacting mixture in the tank, mass of chemical $A$ in the reacting mixture, and total energy of the reacting mixture in the tank.

The mass balance on component $A$ is

$$
\frac{d C_{A}}{d t}=\frac{q}{V}\left(C_{A f}-C_{A}\right)-k_{0} C_{A} \exp \left(-\frac{E}{R T}\right) \varphi_{c}(t) .
$$

The reactor energy balance, assuming constant volume, heat capacity $C_{p}$, density $\rho$ and neglecting changes in potential and kinetic energy is given in equation (7). Consider

$$
\begin{aligned}
\frac{d T}{d t}= & \frac{q}{V}\left(T_{f}-T\right) \\
& +\frac{(-\Delta H) k_{0} C_{A}}{\rho C_{p}} \exp \left(-\frac{E}{R T}\right) \varphi_{c}(t)
\end{aligned}
$$

TABLE 2: Variation in $\delta$ and $\omega_{n}$ with respect to concentration.

\begin{tabular}{lcc}
\hline Concentration $\left(C_{A}\right)$ & Damping factor $(\delta)$ & Frequency $\left(\omega_{n}\right)$ \\
\hline 0.0792 & 0.66 & 3.94 \\
0.0822 & 0.62 & 3.83 \\
0.0851 & 0.58 & 3.74 \\
0.0882 & 0.55 & 3.65 \\
0.0915 & 0.50 & 3.54 \\
0.0949 & 0.46 & 3.45 \\
0.0985 & 0.42 & 3.35 \\
0.1023 & 0.38 & 3.25 \\
0.1062 & 0.34 & 3.16 \\
0.1104 & 0.29 & 3.04 \\
0.1147 & 0.24 & 2.95 \\
0.1196 & 0.20 & 2.84 \\
0.1241 & 0.15 & 2.74 \\
\hline \multicolumn{2}{c}{$\frac{\rho_{c} C_{p c}}{\rho C_{p}} \frac{q_{c}}{V}\left(1-\exp \left(-\frac{h A}{q_{c} \rho C_{p}} \varphi_{h}(t)\right)\right)\left(T_{c f}-T\right)}$.
\end{tabular}

The linearized transfer function model of the CSTR process formulating $C_{A}$ as a control variable takes the form specified in (8) with $\delta$ and $\omega_{n}$ being damping factor and undamped natural frequency, respectively. Consider

$$
\frac{C_{A}(s)}{q_{c}(s)}=\frac{\omega_{n}^{2} k_{p}}{s^{2}+2 \delta \omega_{n} s+\omega_{n}^{2}} .
$$

The model gives a drastic variation in $\delta$ as the operating concentration varies. The variations are mentioned in Table 2. Hence, it is observed that PID parameters [1], designed for a particular operating point, are not suitable to control the process globally. Therefore, there is a need to motivate an insight into the heuristic algorithm that satisfies with the fixed PID parameters, constrained to certain objectives.

\section{Genetic Algorithm}

Genetic algorithm is a random search method that can be used to solve nonlinear system of equations and optimize complex problems. GA uses probabilistic transition rules instead of deterministic rules and handles a population of potential solutions known as individuals or chromosomes that evolve iteratively. Each iteration of the algorithm is termed a generation. The evolution of solutions is simulated through a fitness function and genetic operators such as reproduction, crossover, and mutation [28]. Genetic algorithm as illustrated in Figure 3 is typically initialized with a random population. This population (mating pool) is usually represented by a real-valued number or a binary string called a chromosome. The performance of the individual is measured and assessed by the objective function, which assigns each individual a corresponding number called its fitness.

The fitness of each chromosome is assessed and a survival of the fittest strategy is applied. In this work, the error 


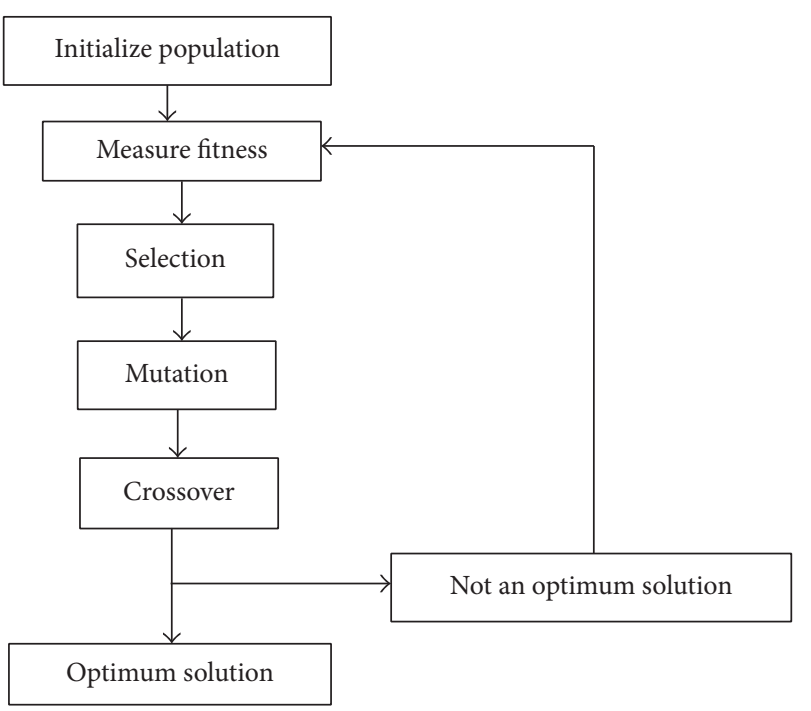

FigURE 3: Flow diagram of genetic algorithm.

value is used to assess the fitness of each chromosome. There are three main operations in a genetic algorithm: reproduction, crossover, and mutation. The sequences of operations involved in GA are described in Figure 3.

\section{Genetic Algorithm Steps}

Step 1. Initialize the parameter with a population of random solutions, such as crossover rate, mutation rate, number of clusters, and number of generations. Determine the coding mode.

Step 2. Compute and evaluate the value of the fitness function.

Step 3. Proceed with crossover and mutation operation and make up the new cluster.

Step 4. Repeat Step 2, till the best value is obtained.

4.1. Coding and Decoding. Genetic algorithms work with a population of strings or chromosomes, instead of considering parameters directly. Hence, to solve our problem, the controller parameter vector should be coded to a string called chromosome. For convenience and simplicity, the binary coding method is chosen. Based on the binary coding method, every element of the parameter vector is coded as a string of length, which consists of zeros and ones for the desired resolution.

4.2. Fitness. Fitness is a measure to evaluate the suitability of a chromosome. By the principle of survival of the fittest, a chromosome with higher fitness value has a higher probability of contributing one or more offspring in the next generation. By employing genetic algorithm, the performance criterion is related to fitness function and optimal PID parameters are derived by minimizing an objective, which inculcates a weighted combination of IAE, ISE, and ITAE.
TABLE 3: Parameters used in genetic algorithm.

\begin{tabular}{lc}
\hline Parameter & Type/value \\
\hline Maximum generations & 100 \\
Population size & 20 \\
Encoding & Binary \\
Selection & Uniform \\
Crossover & Single point crossover \\
Mutation & Uniform \\
\hline
\end{tabular}

TABLE 4: PID parameter range.

\begin{tabular}{lccc}
\hline PID parameters & $K_{c}$ & $T_{I}$ & $T_{d}$ \\
\hline Minimum value & 0 & 0 & 0 \\
Maximum value & 60 & 5 & 2 \\
\hline
\end{tabular}

4.3. Reproduction. Reproduction is a basic operator of genetic algorithm. It is operated on the basis of the survival of the fittest. In each generation, the chromosome of the current population is reproduced or copied into the next generation, according to the reproduction probability $P_{r i}$, which is defined in

$$
P_{r i}=\frac{F_{i}(\theta)}{\sum_{i=1}^{P_{l}} F_{i}(\theta)},
$$

where $P_{l}$ is the population size.

4.4. Crossover. Reproduction directs the search of genetic algorithm towards the best individuals. Crossover operation is performed to exchange the information between any two chromosomes via probabilistic decision in the mating pool and to provide a mechanism to mix chromosomes with the splice point.

4.5. Mutation. In genetic algorithms, however, the gene pool tends to become more and more homogeneous as one better 


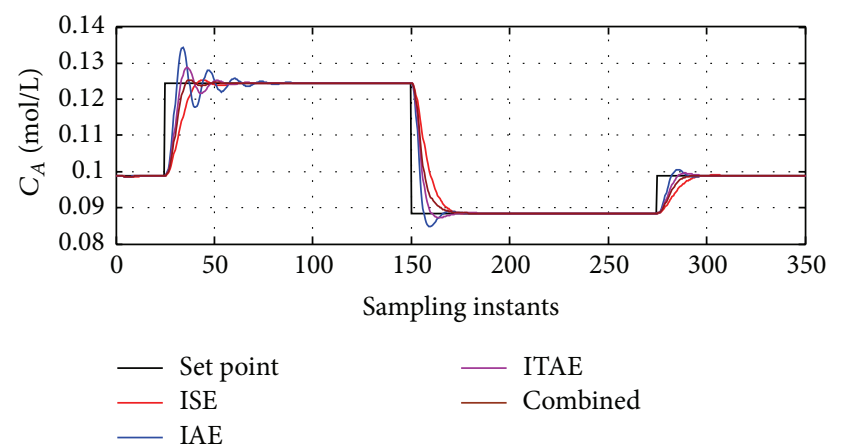

(a)

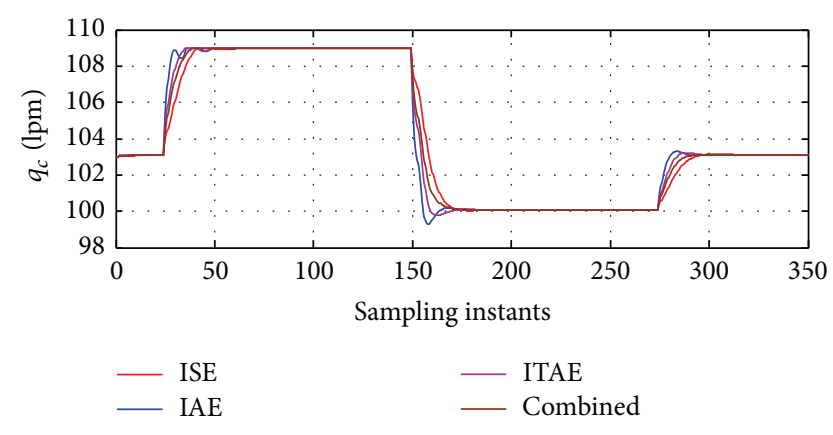

(b)

FIGURE 4: Servo response of CSTR process. (a) Process output. (b) Controller output.

TABle 5: Performance measures under various cost functions.

\begin{tabular}{|c|c|c|c|c|c|c|}
\hline \multirow{3}{*}{ Error measures } & \multicolumn{6}{|c|}{ Sampling instants } \\
\hline & \multicolumn{2}{|r|}{$25: 150$} & \multicolumn{2}{|r|}{$151: 275$} & \multicolumn{2}{|r|}{$276: 350$} \\
\hline & Overshoot (\%) & Settling time (samples) & Overshoot (\%) & Settling time (samples) & Overshoot (\%) & Settling time (samples) \\
\hline ISE & 36.22 & 32 & 0 & 20 & 0 & 20 \\
\hline IAE & 1.03 & 55 & 9.8 & 19 & 5.1 & 19 \\
\hline ITAE & 13.5 & 50 & 2.3 & 19 & 1 & 18 \\
\hline Combined & 1.53 & 23 & 0 & 18 & 0 & 18 \\
\hline
\end{tabular}

gene begins to dominate after several generations and leads to premature convergence of nonoptimal solution. To overcome this undesirable convergence, the third genetic operator mutation is introduced in genetic algorithm with appropriate probability. Mutation is an occasional alternation of the gene from zero to one or from one to zero with the mutation point determined uniformly at random.

Genetic Algorithm Based PID Tuning. It is summarized as follows. GA initially generates a random population, which is implemented with small population size in order to allow the controller to be optimized and converge at a faster rate. The initial population is set by encoding the PID parameters $K_{c}, T_{I}$, and $T_{d}$ into binary strings known as a chromosome. The fitness of each chromosome is calculated by converting its binary string into real value which represents the PID parameters. Each set of PID parameters is passed to PID controller. The complete response of the system for each PID parameter value and its initial fitness value is computed using individual cost functions like ISE, IAE, and ITAE a weighted combination of these three cost functions. This process will go through Steps 2 and 3 until the end of the generations where the best fitness value is achieved. The ultimate aim of GA is to seek global PID values $\left(K_{c}, T_{I}\right.$, and $\left.T_{d}\right)$ with minimum fitness value to operate the CSTR plant in the entire range. The details of GA parameters used in the simulation are shown in Table 3.

\section{Simulation Results}

Simulation using genetic algorithm based PID controller for a CSTR plant, including different performance indices such as
ISE, IAE, and ITAE separately and a weighted combination of these three functions, is carried out for both servo and servo regulatory cases. In all simulation runs, the CSTR process is simulated using the nonlinear first principles model given by (6) and (7) and the true state variable (concentration) is computed by solving the nonlinear differential equation using Matlab 7.0. The controller saturation limit between 97 and $109 \mathrm{lit} / \mathrm{min}$ is considered with initial conditions given by $q_{c}=103 \mathrm{lit} / \mathrm{min}, C_{A}=0.0989 \mathrm{~mol} / \mathrm{lit}$, and $T=438.77 \mathrm{~K}$ and the sampling time of about $0.083 \mathrm{sec}$ is selected for all the simulation studies. The range of PID parameters considered for the simulation is given in Table 4 .

5.1. Servo Performance of CSTR Process. The set point variations as shown in Figure 4(a) have been introduced for assessing the tracking capability of the proposed PID controllers utilizing ISE, IAE, and ITAE separately and a weighted combination of these three functions as objective functions. The weights associated with combined objective function are $w_{1}=0.4, w_{2}=0.2$, and $w_{3}=0.4$. From the response, it is observed that all the controllers are able to track the variation in the reactor concentration when the set point concentration is changed from $0.0989 \mathrm{~mol} / \mathrm{L}$ to $0.1245 \mathrm{~mol} / \mathrm{L}, 0.1245 \mathrm{~mol} / \mathrm{L}$ to $0.0885 \mathrm{~mol} / \mathrm{L}$, and $0.0885 \mathrm{~mol} / \mathrm{L}$ to $0.0989 \mathrm{~mol} / \mathrm{L}$. Weighted GA based PID controller settles faster in all set point transitions. The variation in the controller outputs is presented in Figure 4(b). The performance measures like percentage peak overshoot and settling time are calculated for various objective functions as shown in Table 5. Further, it is evident that the coolant flow rate variation is found to be smooth in all the controllers (refer to Figures 4 and 5). 


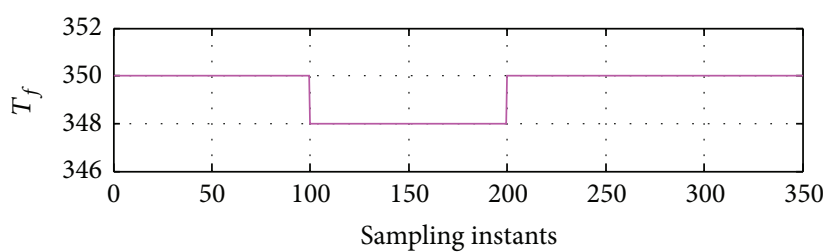

ampling instants

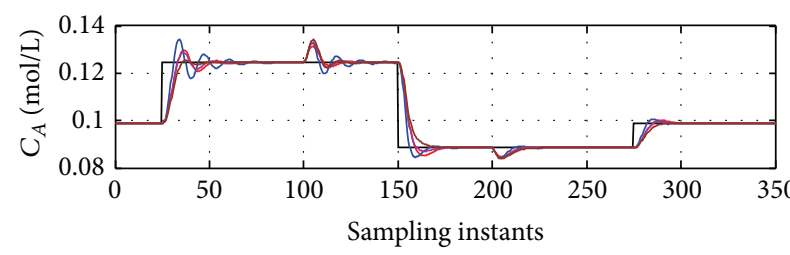

— Set point
— ISE
IAE

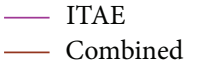

(a)

(b)

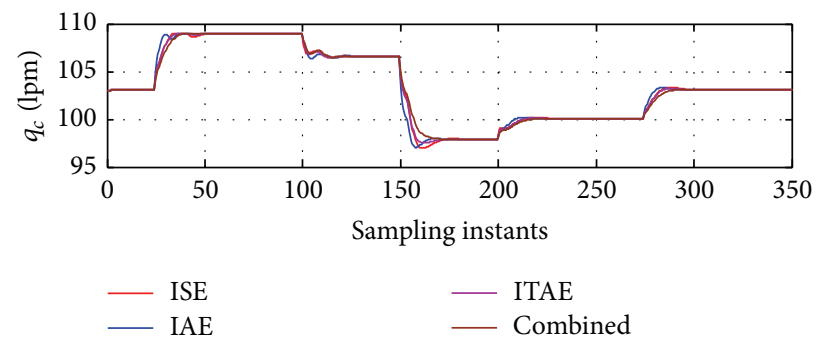

(c)

FIGURE 5: Servo regulatory response of CSTR process. (a) Feed temperature. (b) Process output. (c) Controller output.
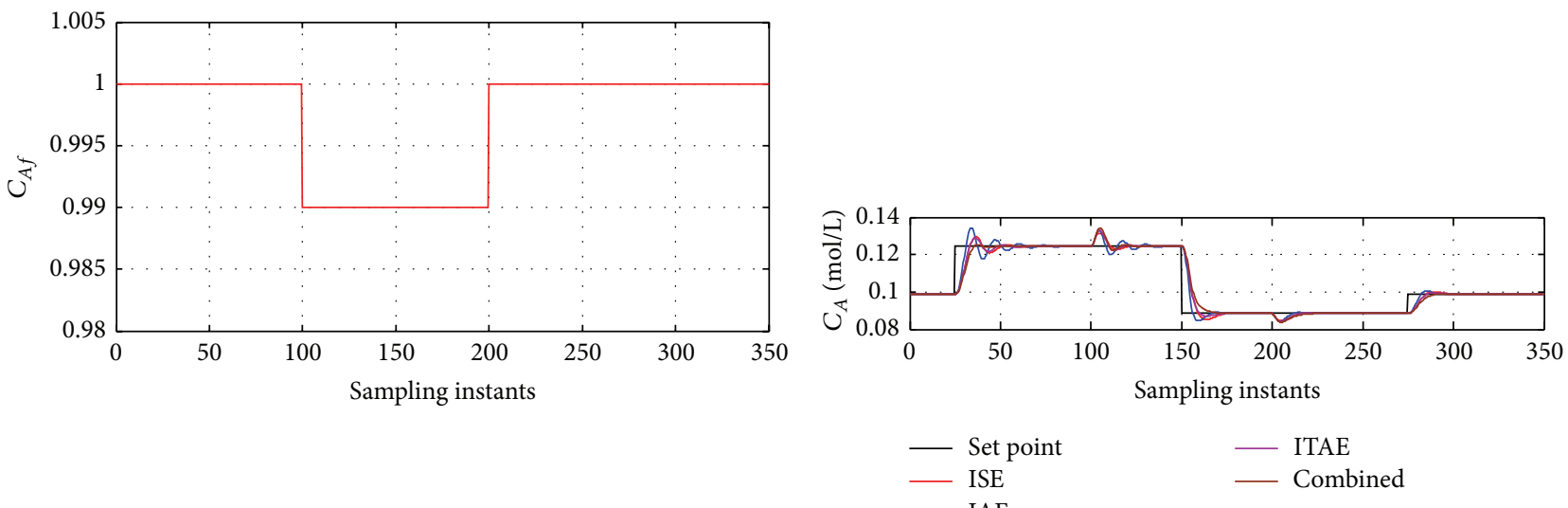

(a)

(b)

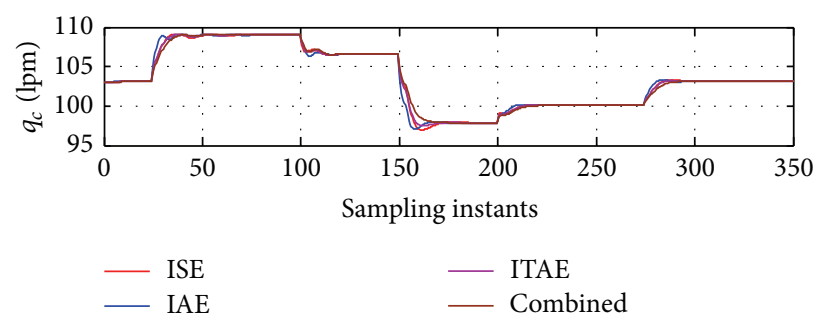

(c)

FIgURE 6: Servo regulatory response of CSTR process. (a) Feed concentration. (b) Process output. (c) Controller output.

Table 5 implies that a weighted combination of cost functions like ISE, IAE, and ITAE gives a better reduction in percentage peak overshoot and settling time compared to using ISE, IAE, and ITAE separately. Overshoot is negligible, both for ISE and for combined cost functions when concentration set point is changed from $0.1245 \mathrm{~mol} / \mathrm{L}$ to $0.0885 \mathrm{~mol} / \mathrm{L}$ and $0.0885 \mathrm{~mol} / \mathrm{L}$ to $0.0989 \mathrm{~mol} / \mathrm{L}$.

5.2. Servo Regulatory Performance of CSTR Process. Simulation studies have been carried out to demonstrate the 


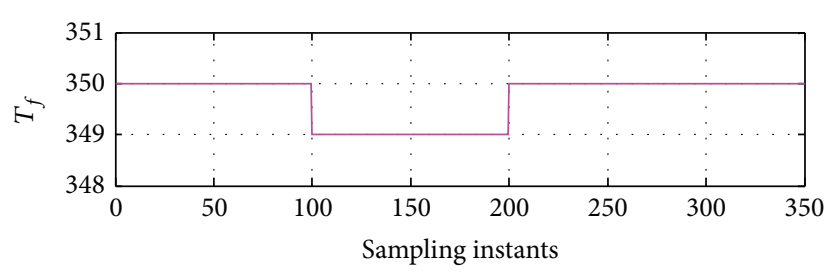

(a)

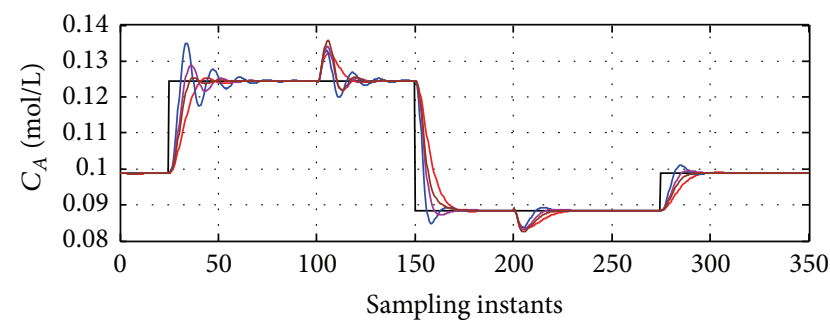

— Set point
ISE
IAE

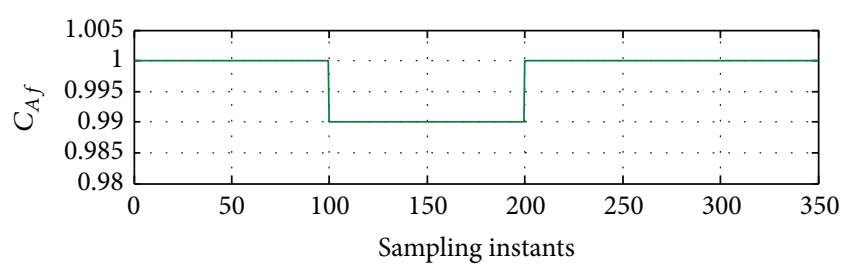

(b)

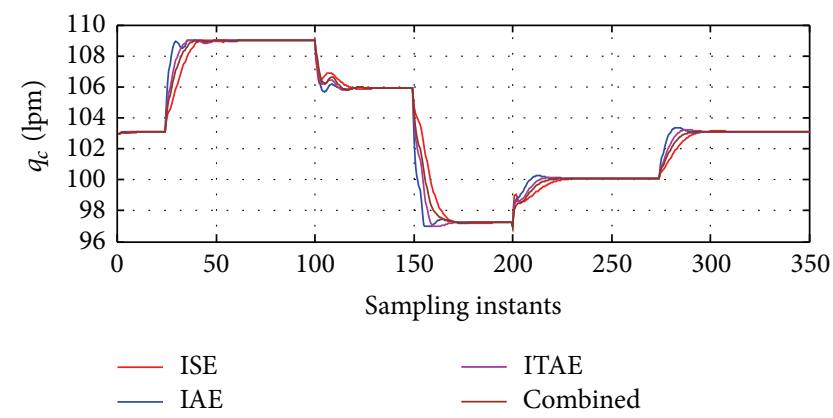

(d)

FIGURE 7: Servo regulatory response of CSTR process. (a) Feed temperature. (b) Feed concentration. (c) Process output. (d) Controller output.

disturbance rejection capability of the CSTR process at nominal and shifted operating point in the presence of change in the feed temperature. A step change in the inlet temperature of magnitude $2 \mathrm{~K}$ (from $350 \mathrm{~K}$ to $348 \mathrm{~K}$ ) has been introduced at the 100th sampling instant and maintained at up to 200th sampling instant (refer to Figure 5(a)).

From 100th sampling instants to 150th sampling instants of Figure 5(b), it can be inferred that the controllers utilizing ISE, IAE, and ITAE separately and a weighted combination of these three functions as objective functions are able to reject the disturbance quickly and bring the reactor concentration back to the nominal value of the set point. The flow rate variation of the controllers is shown in Figure 5(c).

When disturbance persists, a step change in the set point has been introduced at the 150th sampling instant. It can be inferred that all the controllers are able to maintain the concentration at the specific set point, as shown in Figure 5(b). This part of the simulation shows that the controllers are capable of rejecting the disturbance, also at shifted operating points.

Similar observation has been obtained by disturbing the process and by varying the feed concentration as shown in Figure 6(a). The controllers utilizing ISE, IAE, and ITAE separately and a weighted combination of these three functions as objective functions are able to reject the disturbance quickly and bring the reactor concentration back to the nominal value of the set point as shown in Figure 6(b). The flow rate variation of the controllers is shown in Figure 6(c).

Simulation study has been carried out by providing the disturbances feed temperature and feed concentration simultaneously as shown in Figures 7(a) and 7(b). For combined disturbance also, GA based PID controllers with various error goals have given satisfactory performance as shown in Figure $7(\mathrm{c})$. The respective flow rate variation of the controllers is shown in Figure 7(d).

\section{Conclusion}

In this paper, GA based PID controller tuning has been designed and applied to CSTR process. From the simulation studies, we infer that optimized controller parameters obtained by implementing this algorithm with a weighted combination of ISE, IAE, and ITAE as cost indices have achieved satisfactory set point tracking and disturbance rejection in the entire operating range of the CSTR process.

\section{Conflict of Interests}

The authors declare that there is no conflict of interests regarding the publication of this paper.

\section{References}

[1] K. Åström and T. Hagglund, PID Controllers: Theory, Design, and Tuning, Instrument Society of America, Research Triangle Park, NC, USA, 1994.

[2] A. O. Dwyer, Handbook of PI and PID Controller Tuning Rules, Imperial College Press, 3rd edition, 2009.

[3] C. Ou and W. Lin, "Comparison between PSO and GA for parameters optimization of PID controller," in Proceedings of the IEEE International Conference on Mechatronics and Automation (ICMA '06), pp. 2471-2475, IEEE, Luoyang, China, June 2006.

[4] M. Abachizadeh, M. R. H. Yazdi, and A. Y. Koma, "Optimal tuning of PID controllers using artificial bee colony algorithm," in Proceedings of the Advanced Intelligent Mechatronics Conference, pp. 379-384, 2010.

[5] A. Karimi, H. Eskandari, M. Sedighizadeh, A. Rezazadeh, and A. Pirayesh, "Optimal PID controller design for AVR system using new optimization algorithm," International Journal on Technical and Physical Problems of Engineering, vol. 5, no. 15, pp. 123-128, 2013. 
[6] V. Rajinikanth and K. Latha, "Controller parameter optimization for nonlinear systems using enhanced bacteria foraging algorithm," Applied Computational Intelligence and Soft Computing, vol. 2012, Article ID 214264, 12 pages, 2012.

[7] M. Geetha, K. A. Balajee, and J. Jerome, "Optimal tuning of virtual feedback PID controller for a continuous stirred tank reactor (CSTR) using particle swarm optimization (PSO) algorithm," in Proceedings of the 1st International Conference on Advances in Engineering, Science and Management (ICAESM '12), pp. 94-99, March 2012.

[8] R. Vinodha, S. A. Lincoln, and J. Prakash, "Design and implementation of simple adaptive control schemes on simulated model of CSTR process," International Journal of Modelling, Identification and Control, vol. 14, no. 3, pp. 159-169, 2011.

[9] H. Man and C. Shao, "Nonlinear predictive adaptive controller for CSTR process," Journal of Computational Information Systems, vol. 8, no. 22, pp. 9473-9479, 2012.

[10] J. Prakash and R. Senthil, "Design of observer based nonlinear model predictive controller for a continuous stirred tank reactor," Journal of Process Control, vol. 18, no. 5, pp. 504-514, 2008.

[11] J. Prakash and K. Srinivasan, "Design of nonlinear PID controller and nonlinear model predictive controller for a continuous stirred tank reactor," ISA Transactions, vol. 48, no. 3, pp. 273-282, 2009.

[12] R. Senthil, K. Janarthanan, and J. Prakash, "Nonlinear state estimation using fuzzy Kalman filter," Industrial and Engineering Chemistry Research, vol. 45, no. 25, pp. 8678-8688, 2006.

[13] J. Yu and Y. Wu, "Global set-point tracking control for a class of non-linear systems and its application in continuously stirred tank reactor systems," IET Control Theory and Applications, vol. 6, no. 12, pp. 1965-1971, 2012.

[14] M. Delbari, K. Salahshoor, and B. Moshiri, "Adaptive generalized predictive control and model reference adaptive control for CSTR reactor," in Proceedings of the IEEE International Conference on Intelligent Control and Information Processing (ICICIP '10), pp. 165-169, Dalian, China, August 2010.

[15] E. G. Shopova and N. G. Vaklieva-Bancheva, "BASIC-a genetic algorithm for engineering problems solution," Computers and Chemical Engineering, vol. 30, no. 8, pp. 1293-1309, 2006.

[16] J. Zhang, J. Zhuang, H. Du, and S. Wang, "Self-organizing genetic algorithm based tuning of PID controllers," Information Sciences, vol. 179, no. 7, pp. 1007-1018, 2009.

[17] R. A. Krohling and J. P. Rey, "Design of optimal disturbance rejection PID controllers using genetic algorithms," IEEE Transactions on Evolutionary Computation, vol. 5, no. 1, pp. 78-82, 2001.

[18] S. M. G. Kumar, R. Jain, N. Anantharaman, V. Dharmalingam, and K. M. M. S. Begum, "Genetic algorithm based PID controller tuning for a model bioreactor," Indian Chemical Engineer, Indian Institute of Chemical Engineers, vol. 50, no. 3, pp. 214-226, 2008.

[19] A. Bagis, "Determination of the PID controller parameters by modified genetic algorithm for improved performance," Journal of Information Science and Engineering, vol. 23, no. 5, pp. 14691480, 2007.

[20] U. S. Banu and G. Uma, "Fuzzy gain scheduled CSTR with GAbased PID," Chemical Engineering Communications, vol. 195, no. 10, pp. 1213-1226, 2008.

[21] B. Nagaraj and N. Murugananth, "A comparative study of PID controller tuning using GA, EP, PSO and ACO," in Proceedings of the IEEE International Conference on Communication Control and Computing Technologies (ICCCCT '10), pp. 305-313, IEEE, Ramanathapuram, India, October 2010.

[22] W.-D. Chang, "Nonlinear CSTR control system design using an artificial bee colony algorithm," Simulation Modelling Practice and Theory, vol. 31, pp. 1-9, 2013.

[23] W. Wang and X. Jin, "An optimization tuning method of nonlinear non-minimum phase systems and its application to chemical process," in Proceedings of the 26th Chinese Control and Decision Conference (CCDC '14), pp. 4929-4935, Changsha, China, June 2014.

[24] A. Singh and V. Sharma, "Concentration control of CSTR through fractional order PID controller by using soft techniques," in Proceedings of the 4th International Conference on Computing, Communications and Networking Technologies (ICCCNT '13), pp. 1-6, Tiruchengode, India, July 2013.

[25] A. Y. Jaen-Cuellar, R. D. J. Romero-Troncoso, L. MoralesVelazquez, and R. A. Osornio-Rios, "PID-controller tuning optimization with genetic algorithms in servo systems," International Journal of Advanced Robotic Systems, vol. 10, p. 324, 2013.

[26] M. Pottman and D. E. Seborg, "Identification of non-linear processes using reciprocal multiquadric functions," Journal of Process Control, vol. 2, no. 4, pp. 189-203, 1992.

[27] B. W. Bequette, Process Control-Modelling, Design and Simulation, Prentice Hall, New Delhi, India, 2004.

[28] K. F. Man, K. S. Tang, and S. Kwong, "Genetic algorithms: concepts and applications," IEEE Transactions on Industrial Electronics, vol. 43, no. 5, pp. 519-534, 1996. 

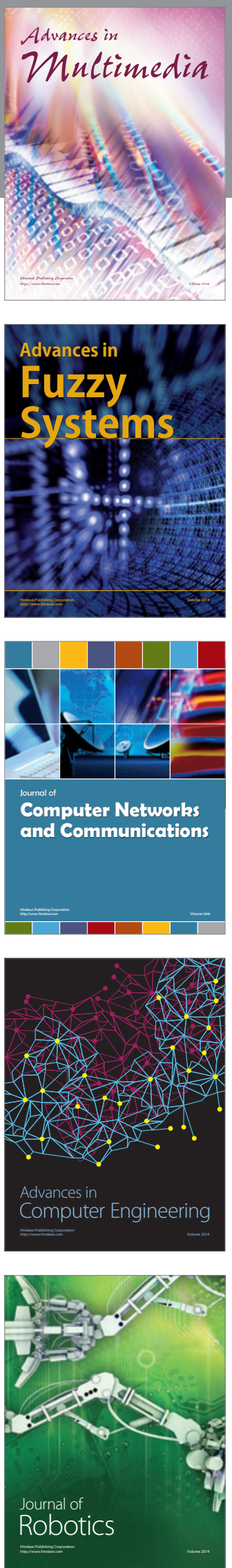

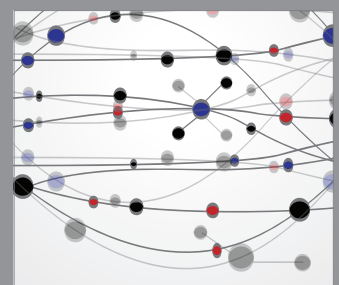

The Scientific World Journal
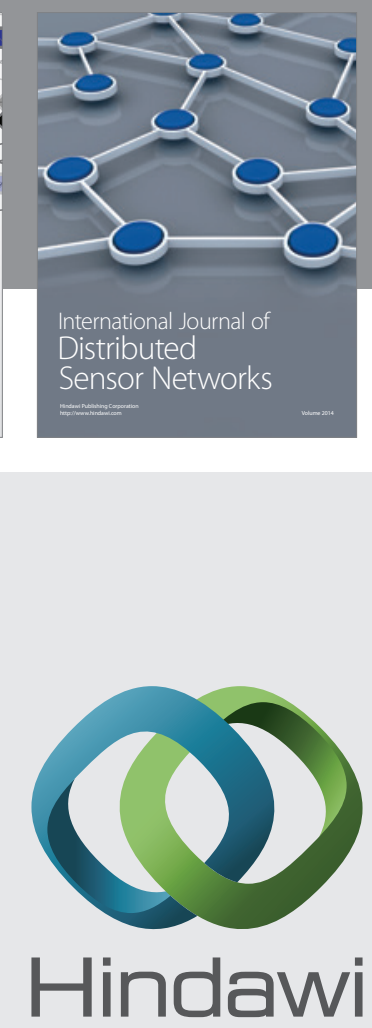

Submit your manuscripts at

http://www.hindawi.com
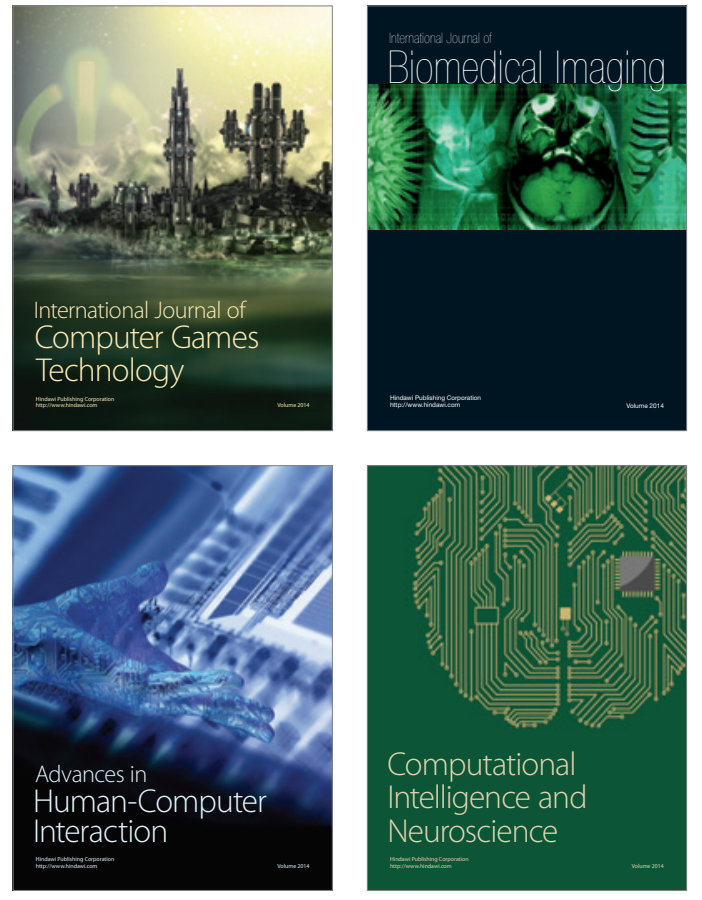
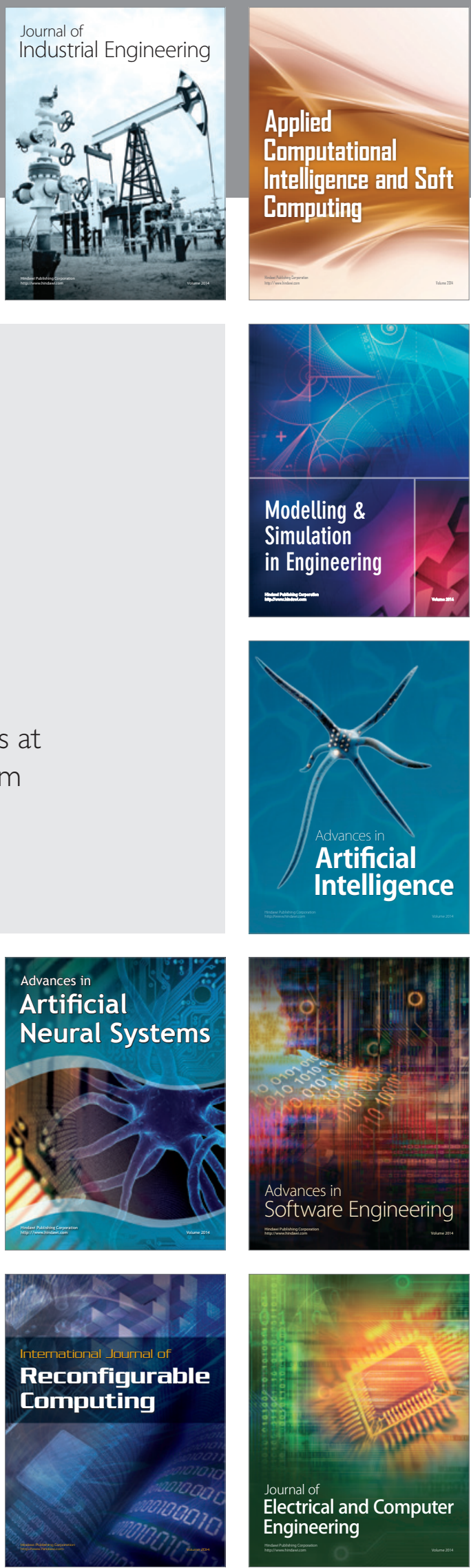